MOLN-D-18-00675. (Revised)

\title{
Recapitulation of pathological TDP-43 features in immortalized lymphocytes from sporadic ALS patients
}

Diana Posa ${ }^{1, \S}$, Loreto Martínez-González 2, , Fernando Bartolomé ${ }^{3,4, \S}$, Siranjeevi Nagaraj1,5, Gracia Porrasi ${ }^{1}$, Ana Martínez ${ }^{2, *}$ and Angeles Martín-Requero, ${ }^{1, *}$

$\S$ These authors contributed equally

${ }^{1}$ Department of Cellular and Molecular Medicine, Centro de Investigaciones Biológicas (CSIC) Madrid, Spain.

${ }^{2}$ Department of Structural and Chemical Biology, Centro de Investigaciones Biológicas (CSIC) Madrid, Spain.

${ }^{3}$ Neurodegenerative Disorders group, Instituto de Investigacion Hospital 12 de Octubre, Spain.

${ }^{4}$ CIBER de Enfermedades neurodegenerativas (CIBERNED), Spain.

${ }^{5}$ Laboratory of Preclinical Testing of Higher Standard, Nencki Institute of Experimental Biology, Polish Academy of Science, Pasteur 3 St., 02-093 Warsaw, Poland

Key words: ALS, lymphoblasts, TDP-43; CK-1 $\delta$

Address for correspondence:

Dr. Ángeles Martín-Requero, Dr. Ana Martínez

Centro de Investigaciones Biológicas (CSIC)

Ramiro de Maeztu 9

28040 Madrid, SPAIN

Phone: 34-91-837-3112

Fax: 34-91-536-0432

Email: amrequero@cib.csic.es

Email: ana.martinez@csic.es 


\begin{abstract}
Amyotrophic Lateral Sclerosis (ALS) is a fatal progressive neurodegenerative disorder of still unknown etiology, that results in loss of motoneurons, paralysis and death, usually between 2-4 years from onset. There are no currently available ALS biomarkers to support early diagnosis and to facilitate the assessment of the efficacy of new treatments. Since ALS is considered a multisystemic disease, here we have investigated the usefulness of immortalized lymphocytes from sporadic ALS patients to study TDP-43 homeostasis as well as to provide a convenient platform to evaluate TDP-43 phosphorylation as a novel therapeutic approach for ALS. We report here that lymphoblasts from ALS patients recapitulate the hallmarks of TDP-43 processing in affected motoneurons, such as increased phosphorylation, truncation and mislocalization of TDP-43. Moreover, modulation of TDP-43 by an in-house designed protein casein kinase-1 $\delta(\mathrm{CK}-1 \delta)$ inhibitor, IGS3.27, reduced phosphorylation of TDP-43, and normalized the nucleo-cytosol translocation of TDP-43 in ALS lymphoblasts. Therefore, we conclude that lymphoblasts, easily accessible cells, from ALS patients could be a useful model to study pathological features of ALS disease and a suitable platform to test the effects of potential disease-modifying drugs even in a personalized manner.
\end{abstract}




\section{INTRODUCTION}

ALS is a neurodegenerative disorder characterized by progressive degeneration of upper and lower motor neurons leading to weakness of affected muscles and eventually to muscular paralysis. Most cases of ALS are sporadic (sALS), however about $5 \%$ of cases have a family history of ALS (fALS). About $20 \%$ of cases with autosomal dominant fALS and $2 \%$ of patients with sALS show mutations in superoxide dismutase (SOD1) gene [1].

Other genes causing fALS are VCP, TARDBP, SQSTM1, C9ORF72, OPTN, and UBQLN2 [2-12]. The physiological functions and properties of these genes can be grouped according to their involvement in (i) protein quality control, (ii) cytoskeletal dynamics, (iii) RNA homeostasis, and (iv) DNA damage response [13].

A hallmark of both sporadic and familial ALS is the presence of abnormal protein aggregates in the cytoplasm of neuronal and glial cells, which contain the trans-activating response region DNA binding protein of $43 \mathrm{kDa}$, known as TDP-43, as the main component [14]. The pathogenic role of TDP-43 in ALS was reinforced by the finding of mutations in the TARDBP gene in some ALS patients [15]. TDP-43 is a highly conserved 414-amino acid nuclear protein and ubiquitously expressed [16]. TDP-43 contains different RNA recognition motifs, such as a nuclear localization sequence (NLS), a nuclear export signal [17], and a glycine-rich C-terminus that mediates protein-protein interactions [18]. The C-terminus of TDP-43 is the site of the majority of ALS causing mutations identified in human disease, indicating this region of the protein may mediate pathological protein modifications and aggregation. The $\mathrm{C}$ - terminus of TDP-43 is truncated, phosphorylated and forms inclusions in tissues affected by ALS [2, 19, 20]. TDP-43 pre-dominantly resides in the nucleus but is capable of nucleo-cytoplasmic shuttling [17]. Indeed, abnormal localization of TDP-43 in the cytoplasmic compartment, 
either in its native form or post-translationally modified forms had been extensively identified by histochemical studies on brain cortex and spinal cord of ALS patients [21]. The phosphorylation of TDP-43 in tandem serine 409 and 410 characterizes most TDP43 proteinopathy cases [20]. Protein casein kinase-1 (CK-1) is considered the main kinase able to phosphorylate TDP-43 in vitro and in vivo $[22,23]$. Moreover, the activity of CK1 was found to be upregulated in spinal cord tissue in ALS [24] and therefore could play a role in disease pathogenesis.

There is increasing evidence that ALS has to be regarded as multisystem degeneration as it also presents non-motor symptoms [25, 26]. In particular, peripheral blood mononuclear cells (PBMC) or skin fibroblasts display traits of the disease such as downregulation of Bcl-2 [27, 28], increased nitrative stress [28], intracellular calcium dysregulation [29], glutamatergic dysfunction [30] and mitochondrial dysfunction [31] [32]. Regarding TDP-43 proteinopathy, it was reported mislocalization of TDP-43 in circulating lymphomonocytes from ALS patients carrying TARDBP mutations as well in some of sALS individuals [33], suggesting that cytoplasmic TDP-43 levels in peripheral cells could be a plausible biomarker for monitoring disease progression.

This work was undertaken to further study TDP-43 pathological features in immortalized lymphocytes from sALS patients. To this end phosphorylation status of full-length and truncated TDP-43, as well as the subcellular localization of TDP-43 were determined by Western blotting and confocal microscopy. Here we report that lymphoblastoid cell lines (LCLs) from ALS patients recapitulate the pathogenic mechanisms thought to be involved in the neurodegenerative process in ALS, such as increased phosphorylation and truncation of TDP-43 as well as altered subcellular distribution of TDP-43. In addition,

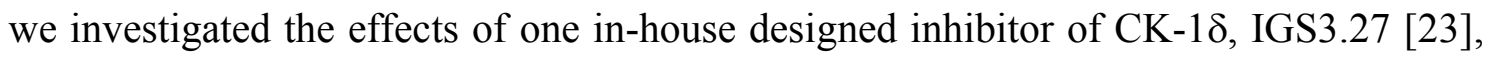


modulating TDP-43 phosphorylation and processing of TDP-43. It is concluded that LCLs from sALS patients could serve as a human-cell based screening platform for drug discovery. 


\section{MATERIALS AND METHODS}

\section{Materials.}

All components for cell culture were obtained from Invitrogen (Barcelona, Spain). PVDF (polyvinylidene difluoride) membranes for Western blots were purchased from Bio-Rad (Richmond, CA, USA). The enhanced chemiluminiscence (ECL) system was from Amersham (Uppsala, Sweden). The $N$-benzothiazolyl-2-phenyl-acetamide derivative, CK-1 $\delta$ inhibitor, IGS3.27, was synthesized in our laboratory as previously described [23]. Antibodies against human TDP-43 (10782-2-AP) and phospho (409/410)-TDP-43 (22309-1AP) were obtained from Proteintech (Mancheser, UK). Antibodies against $\beta$ actin (sc-81178), $\alpha$-tubulin (sc-23948), and GAPDH (sc-25778) were obtained from Santa Cruz Biotechnologies (Santa Cruz, CA, USA) and anti-Lamin B1 was purchased from Calbiochem (Billerica, MA, USA).

\section{Cell lines}

\section{Lymphoblastic cell lines}

Peripheral blood samples of all the individuals enrolled in this study were collected after written informed consent of the patients or their relatives (demographic information is presented in Table 1) to establish the lymphoblastoid cell lines (LCLs) as previously described (Ibarreta et al, 1997), by infecting peripheral blood lymphocytes with the Epstein Barr virus (EBV). All study protocols were approved by the Hospital Doce de Octubre and the Spanish Council of Higher Research Institutional Review Board and are in accordance with National and European Union Guidelines. All patients were diagnosed by applying the revised El Escorial criteria [34]. All patients were negative for SOD1 
mutations, and only one of them have a hexanucleotide expansion (1894 repeats) in the C9orf72 gene.

Lymphoblastoid cells lines were grown in suspension in T flasks in an upright position, in approximately $8 \mathrm{ml}$ of RPMI-1640 medium that contained $2 \mathrm{mM}$ L-glutamine, 100 $\mu \mathrm{g} \cdot \mathrm{ml}^{-1}$ streptomycin/penicillin and 10\% (v/v) fetal bovine serum (FBS) and maintained in a humidified $5 \% \mathrm{CO}_{2}$ incubator at $37^{\circ} \mathrm{C}$. Fluid was routinely changed every three days by removing the medium above the settled cells and replacing it with an equal volume of fresh medium.

\section{Immunoblotting analysis.}

Cells were collected by centrifugation, washed with PBS and total protein extracts were obtained by lysing them as previously described [35]. To separate the cytosolic and nuclear fractions, cells were harvested, washed in PBS and then lysed in ice-cold hypotonic buffer as previously described [36]. After extraction on ice for $15 \mathrm{~min}, 0.5 \%$ Nonidet P-40 was added and the lysed cells were centrifuged at 4,000 rpm for $10 \mathrm{~min}$. Supernatants containing cytosolic proteins were separated and pellets were resuspended in hypertonic buffer to lysate the nucleus [36]. The protein content of the extracts was determined by the Pierce BCA Protein Assay kit (Thermo Scientific). Equal amounts of proteins were resolved by SDS-polyacrylamide gel electrophoresis. The proteins were then transferred to polyvinylidene fluoride (PVDF) membranes and immunodetected, as previously described [35]. The following primary antibodies were used, TDP-43 (1:1000); phospho-(S409/410)-TDP-43 (1:500); $\beta$-actin (1:500); $\alpha$-tubulin (1:1000) and Lamin B1 (1:1000). Signals from the primary antibodies were amplified using speciesspecific antisera conjugated with horseradish peroxidase (Bio-Rad) and detected with a 
chemiluminiscent substrate detection system ECL. Relative band intensities were quantified using Image Studio Lite software (LI-COR Biotechnology, NE, USA).

\section{Immunofluorescence}

Cells $\left(1 \times 10^{6} \mathrm{x} \mathrm{ml}^{-1}\right)$ were fixed for $30 \mathrm{~min}$ in $4 \%$ paraformaldehyde in PBS and blocked and permeabilized with $0.5 \%$ TritonX-100 in PBS- $0.5 \%$ BSA for $60 \mathrm{~min}$ at room temperature. Cells were attached to poly-L-lysine coated coverslips using the Cytospin centrifuge at $700 \mathrm{rpm}$ for 7 minutes before they incubated overnight with anti-TDP43 polyclonal antibody. After removing the primary antibody, cells were washed with PBS and incubated with Alexa Fluor 488-conjugated anti-rabbit antibody alone or in combination with phaloidin for cytoskeleton staining. For nuclear staining, the preparations were mounted on ProLong ${ }^{\circledR}$ Gold Antifade Reagent with DAPI (Thermo Fisher) allowing nuclear visualization. High-resolution images were acquired for $\sim 30$ cells per group in $\mathrm{n}=3$ independent experiments using a confocal microscope Zeiss 510 equipped with a META detection system and a $63 \times$ oil immersion objective. Cytosolic TDP-43 levels per cell were quantified using the Volocity software (PerkinElmer, Waltham, MA).

\section{Statistical analysis}

Statistical analyses were performed with Graph Pad Prism 6 (La Jolla, CA, USA). All the statistical data are presented as mean \pm standard error of the mean (SEM). Normality was checked with the Shapiro-Wilk test. Parametric tests were therefore used in the statistical analysis. Statistical significance was estimated by the Student's $t$ test or by analysis of variance (ANOVA) followed by the Fisher's LSD test for multiple comparisons. A value of $p<0.05$ was considered significant. 


\section{RESULTS}

\section{TDP-43 phosphorylation in control and ALS lymphoblasts.}

TDP-43 phosphorylation was assessed by Western blotting using a phospho-specific (Ser 409/410) anti-TDP-43 antibody in lymphoblasts from control and ALS patients. As shown in Fig. 1, this antibody recognizes three major bands corresponding to the sizes 43,35 and $25 \mathrm{kDa}$. It can be observed a clear increase in the phosphorylation of the full length as well as in the truncated TDP-43 fragments in lymphoblasts from ALS patients

(Fig. 1a, b). In contrast we did not find differences in total TDP-43 levels between control or ALS cells (Fig. 1b). Fig. 1c summarizes the ratio pTDP-43/TDP-43 (full length and truncated) obtained in all the LCLs used in this work.

\section{Subcellular distribution of TDP-43 in control and ALS lymphoblasts}

Since the balance between nuclear and cytosolic content of TDP-43 is thought to be disrupted in the nervous system (SN) of ALS patients, we seek to elucidate whether TDP43 also accumulates in lymphoblasts from ALS patients. For this purpose, we performed nuclear and cytoplasmic fractionation and analyzed the protein extracts by Western blot analysis. As shown in Fig. 2, there was an increase in the cytosolic content of TDP-43 in ALS cells compared with control lymphoblasts, whereas opposite changes occur in nuclear TPD-43. Similar results were obtained by immunofluorescence analyzing cytosolic TDP-43 levels in ALS cells compared to lymphoblasts from controls (Fig. 3).

Effects of IGS 3.27 on phosphorylation status of TDP-43 in control and ALS lymphoblasts. 
The isoform $\delta$ of CK-1 (CK1- $\delta)$ is known to phosphorylate different serine and threonine sites on TDP-43 protein, and thus qualifies as a potential target for ALS treatment [22]. For this reason, we sought to evaluate the effects of a selective in-house designed inhibitor of CK-1 [23], IGS3.27. For these experiments, cells were incubated in the absence or presence of $5 \mu \mathrm{M}$ inhibitor for $24 \mathrm{~h}$. This concentration was chosen based in previous work from this laboratory [37]. Fig. 4 shows that IGS3.27 was able to partially block the enhanced TDP-43 phosphorylation of TDP-43 in ALS lymphoblasts, without affecting total levels of non-phosphorylated TDP-43. Moreover, treatment with IGS3.27 decreased the cytosolic TDP-43 levels, preventing the cytosolic accumulation of TDP-43 in ALS lymphoblasts, without affecting significantly TDP-43 levels in control cells (Fig. 5). Finally, we sought to evaluate the effects of IGS3.27 on subcellular localization of TDP43. As shown in Fig 5, IGS 3.27 treatment had no appreciable effects on control cells, but it was able to decrease the accumulation of cytosolic TDP-43 in ALS lymphoblasts, restoring in addition normal nuclear levels of this protein. Together, these results suggest that IGS3.27 prevents the pathological exit of TDP-43 from the nucleus in lymphoblasts from ALS patients. 


\section{DISCUSSION}

ALS is a multisystemic disease, in which pathological processes extend beyond the CNS [38]. In particular, PBMCs from ALS patients were reported to display to display traits of the disease including oxidative stress, $\mathrm{Ca}^{2+}$ fluxes or mitochondrial dysfunction (2932). Recent studies have used this type of cells to look for transcriptional alterations to assess pathogenesis in ALS, and for example, an expression analysis of protein homeostasis pathways in the PBMCs of sALS patients had revealed alterations in the transcription of genes involved in the proteasome and autophagy processes [38]. Here, we show that immortalized lymphocytes from sporadic ALS patients recapitulate the TDP-43 abnormalities observed in neuronal cells of ALS cases. TDP-43 pathological processing includes translocation from nucleus to cytoplasm, truncation, and hyperphosphorylation. These observations support the usefulness of lymphoblasts from ALS patients to mechanistic studies, particularly in sporadic cases, for which no experimental models are available.

By using a phosphorylation-dependent antibody we detected quantitative changes in phosphorylated full-length and truncated TDP-43 protein in lymphoblasts from sporadic ALS patients. In contrast, no significant changes were found in non-phosphorylated TDP43 levels on ALS cells when compared with control lymphoblasts. Both, full-length pTDP-43/TDP-43 and fragmented pTDP-43/TDP-43 ratios are higher in ALS than in control cells. The changes in TDP-43 phosphorylation were accompanied by alteration in the balance between cytosolic and nuclear localization of the TDP-43 protein. Our results indicate that there is a significant reduction in the levels of nuclear TDP-43 in ALS lymphoblasts, together with TDP-43 accumulation in the cytosolic compartment. As far as we know this is the first report showing increased levels of full and truncated pTDP- 
43 in lymphoblasts derived from sALS patients. Our results confirm a previous report showing the accumulation of TDP-43 in the cytoplasm of circulating lymphomonocytes [33]. Together these observations demonstrate that peripheral cells from ALS patients recapitulate the increased phosphorylation and subcellular mislocalization of TDP-43 that characterizes the altered motor neurons of ALS patients [19-21]. On the other hand, the results presented herein are in accordance with previous reports from this laboratory showing alterations in TDP-43 phosphorylation and in TDP-43 translocation from the nucleus to cytosol in lymphoblasts of FTLD-TDP patients [37, 40, 41]. These observations give further support to the idea of an ALS-FTLD continuum [42, 43].

It is believed that abnormal phosphorylation of TDP-43 at the Ser 409/410 is a critical step in ALS and other neurodegenerative diseases. Protein casein kinase $1 \delta$ is considered the main kinase involved in TDP-43 phosphorylation [22]. For these reasons, the search for specific inhibitors of these enzymes has become a challenge for the treatment of these proteinopathies [44]. On these grounds, we developed a number of potent CK-1 $\delta$ inhibitors, able to prevent TDP-43 phosphorylation in vitro and neurotoxicity in vivo [23]. Here we have evaluated the efficacy of one of these kinase inhibitors in abrogating the pathological TDP-43 changes of ALS lymphoblasts. The benzothiazole IGS3.27 was shown to significantly inhibit the endogenous TDP-43 phosphorylation, and what it is important to reduce TDP-43 accumulation in ALS cells, restoring the normal ratio of nuclear/cytosolic levels of TDP-43. These findings are in accordance with a previous report showing that overexpression of active $\mathrm{CK}-1 \delta$ promotes mislocalization and accumulation of cytosolic phosphorylated TDP-43 in cultured neuroblastoma SH-SY5Y cells [45]. Therefore, it seems that modulating TDP-43 phosphorylation may contribute to regulate the nucleo-cytoplasm shuttle of TDP-43. Similar results were obtained in peripheral cells from FTLD-TDP patients [37]. Thus, immortalized lymphocytes from 
ALS or FTLD-TDP patients recapitulate the pathological features of these diseases, hyperphosphorylation, truncation and cytosolic accumulation of TDP-43. Moreover, our results indicate that inhibiting the enzymatic activity of CK-1 $\delta$ rescue the normal levels of phosphorylated TDP-43 and prevents its cytosolic accumulation, recovering its usual homeostasis. Taken together, these observations reinforce the use of lymphoblasts from patients to test disease-modifying drugs, adding further support to the idea that $\mathrm{CK}-1 \delta$ inhibitors could be considered as a useful pharmacological approach for treatment of ALS/FTLD-TDP.

\section{Acknowledgements}

This work has been supported by grants from MINECO (CTQ2015-66313-R to AMR and SAF2016-76693-R to AM) and Madrid Community (B2017/BMD3813 ELA-Madrid). FB holds a contract from CIBERNED. We are grateful to the patients and healthy volunteers and Drs. AG. Redondo and J. Esteban for providing samples.

\section{Conflict of interest}

None of the authors has any conflict of interest to report 


\section{REFERENCES}

1. Rosen D.R., Siddique T., Patterson D., Figlewicz D.A., Sapp P., Hentati A., Donaldson D., Goto J., O'Regan J.P., Deng H.X., et al. (1993) Mutations in Cu/Zn superoxide dismutase gene are associated with familial amyotrophic lateral sclerosis. Nature 362 (6415):59-62. doi:10.1038/362059a0

2. Arai T., Hasegawa M., Akiyama H., Ikeda K., Nonaka T., Mori H., Mann D., Tsuchiya K., Yoshida M., Hashizume Y., Oda T. (2006) TDP-43 is a component of ubiquitinpositive tau-negative inclusions in frontotemporal lobar degeneration and amyotrophic lateral sclerosis. Biochem Biophys Res Commun 351 (3):602-611. doi:10.1016/j.bbrc.2006.10.093

3. Groen E.J., Fumoto K., Blokhuis A.M., Engelen-Lee J., Zhou Y., van den Heuvel D.M., Koppers M., van Diggelen F., van Heest J., Demmers J.A., Kirby J., Shaw P.J., Aronica E., Spliet W.G., Veldink J.H., van den Berg L.H., Pasterkamp R.J. (2013) ALS-associated mutations in FUS disrupt the axonal distribution and function of SMN. Hum Mol Genet 22 (18):3690-3704. doi:10.1093/hmg/ddt222

4. Johnson J.O., Mandrioli J., Benatar M., Abramzon Y., Van Deerlin V.M., Trojanowski J.Q., Gibbs J.R., Brunetti M., Gronka S., Wuu J., Ding J., McCluskey L., MartinezLage M., Falcone D., Hernandez D.G., Arepalli S., Chong S., Schymick J.C., Rothstein J., Landi F., Wang Y.D., Calvo A., Mora G., Sabatelli M., Monsurro M.R., Battistini S., Salvi F., Spataro R., Sola P., Borghero G., Galassi G., Scholz S.W., Taylor J.P., Restagno G., Chio A., Traynor B.J. (2010) Exome sequencing reveals VCP mutations as a cause of familial ALS. Neuron 68 (5):857-864. doi:10.1016/j.neuron.2010.11.036 
5. Kwiatkowski T.J., Jr., Bosco D.A., Leclerc A.L., Tamrazian E., Vanderburg C.R., Russ C., Davis A., Gilchrist J., Kasarskis E.J., Munsat T., Valdmanis P., Rouleau G.A., Hosler B.A., Cortelli P., de Jong P.J., Yoshinaga Y., Haines J.L., Pericak-Vance M.A., Yan J., Ticozzi N., Siddique T., McKenna-Yasek D., Sapp P.C., Horvitz H.R., Landers J.E., Brown R.H., Jr. (2009) Mutations in the FUS/TLS gene on chromosome 16 cause familial amyotrophic lateral sclerosis. Science 323 (5918):1205-1208. doi:10.1126/science. 1166066

6. Mackenzie I.R., Frick P., Neumann M. (2014) The neuropathology associated with repeat expansions in the C9ORF72 gene. Acta neuropathologica 127 (3):347-357. doi:10.1007/s00401-013-1232-4

7. Waibel S., Neumann M., Rabe M., Meyer T., Ludolph A.C. (2010) Novel missense and truncating mutations in FUS/TLS in familial ALS. Neurology 75 (9):815-817. doi:10.1212/WNL.0b013e3181f07e26

8. Ravits J., Appel S., Baloh R.H., Barohn R., Brooks B.R., Elman L., Floeter M.K., Henderson C., Lomen-Hoerth C., Macklis J.D., McCluskey L., Mitsumoto H., Przedborski S., Rothstein J., Trojanowski J.Q., van den Berg L.H., Ringel S. (2013) Deciphering amyotrophic lateral sclerosis: what phenotype, neuropathology and genetics are telling us about pathogenesis. Amyotrophic lateral sclerosis \& frontotemporal degeneration 14 Suppl 1:5-18. doi:10.3109/21678421.2013.778548

9. Tan C.F., Eguchi H., Tagawa A., Onodera O., Iwasaki T., Tsujino A., Nishizawa M., Kakita A., Takahashi H. (2007) TDP-43 immunoreactivity in neuronal inclusions in familial amyotrophic lateral sclerosis with or without SOD1 gene mutation. Acta neuropathologica 113 (5):535-542. doi:10.1007/s00401-007-0206-9 
10. Teyssou E., Takeda T., Lebon V., Boillee S., Doukoure B., Bataillon G., Sazdovitch V., Cazeneuve C., Meininger V., LeGuern E., Salachas F., Seilhean D., Millecamps S. (2013) Mutations in SQSTM1 encoding p62 in amyotrophic lateral sclerosis: genetics and neuropathology. Acta neuropathologica 125 (4):511-522. doi:10.1007/s00401013-1090-0

11. Van Deerlin V.M., Leverenz J.B., Bekris L.M., Bird T.D., Yuan W., Elman L.B., Clay D., Wood E.M., Chen-Plotkin A.S., Martinez-Lage M., Steinbart E., McCluskey L., Grossman M., Neumann M., Wu I.L., Yang W.S., Kalb R., Galasko D.R., Montine T.J., Trojanowski J.Q., Lee V.M., Schellenberg G.D., Yu C.E. (2008) TARDBP mutations in amyotrophic lateral sclerosis with TDP-43 neuropathology: a genetic and histopathological analysis. The Lancet Neurology 7 (5):409-416. doi:10.1016/s14744422(08)70071-1

12. Yokoseki A., Shiga A., Tan C.F., Tagawa A., Kaneko H., Koyama A., Eguchi H., Tsujino A., Ikeuchi T., Kakita A., Okamoto K., Nishizawa M., Takahashi H., Onodera O. (2008) TDP-43 mutation in familial amyotrophic lateral sclerosis. Ann Neurol 63 (4):538-542. doi:10.1002/ana.21392

13. Weishaupt J.H., Hyman T., Dikic I. (2016) Common Molecular Pathways in Amyotrophic Lateral Sclerosis and Frontotemporal Dementia. Trends in molecular medicine 22 (9):769-783. doi:10.1016/j.molmed.2016.07.005

14. Neumann M. (2009) Molecular neuropathology of TDP-43 proteinopathies. International journal of molecular sciences $10 \quad$ (1):232-246. doi:10.3390/ijms 10010232 
15. Kabashi E., Lin L., Tradewell M.L., Dion P.A., Bercier V., Bourgouin P., Rochefort D., Bel Hadj S., Durham H.D., Vande Velde C., Rouleau G.A., Drapeau P. (2010) Gain and loss of function of ALS-related mutations of TARDBP (TDP-43) cause motor deficits in vivo. Hum Mol Genet 19 (4):671-683. doi:10.1093/hmg/ddp534

16. Ou S.H., Wu F., Harrich D., Garcia-Martinez L.F., Gaynor R.B. (1995) Cloning and characterization of a novel cellular protein, TDP-43, that binds to human immunodeficiency virus type 1 TAR DNA sequence motifs. Journal of virology 69 (6):3584-3596

17. Winton M.J., Igaz L.M., Wong M.M., Kwong L.K., Trojanowski J.Q., Lee V.M. (2008) Disturbance of nuclear and cytoplasmic TAR DNA-binding protein (TDP-43) induces disease-like redistribution, sequestration, and aggregate formation. J Biol Chem 283 (19):13302-13309. doi:10.1074/jbc.M800342200

18. Wang H.Y., Wang I.F., Bose J., Shen C.K. (2004) Structural diversity and functional implications of the eukaryotic TDP gene family. Genomics 83 (1):130-139

19. Neumann M., Sampathu D.M., Kwong L.K., Truax A.C., Micsenyi M.C., Chou T.T., Bruce J., Schuck T., Grossman M., Clark C.M., McCluskey L.F., Miller B.L., Masliah E., Mackenzie I.R., Feldman H., Feiden W., Kretzschmar H.A., Trojanowski J.Q., Lee V.M. (2006) Ubiquitinated TDP-43 in frontotemporal lobar degeneration and $\begin{array}{lllll}\text { amyotrophic lateral sclerosis. } & \text { Science } & 314 & \text { (5796):130-133. }\end{array}$ doi:10.1126/science. 1134108

20. Hasegawa M., Arai T., Nonaka T., Kametani F., Yoshida M., Hashizume Y., Beach T.G., Buratti E., Baralle F., Morita M., Nakano I., Oda T., Tsuchiya K., Akiyama H. 
(2008) Phosphorylated TDP-43 in frontotemporal lobar degeneration and amyotrophic lateral sclerosis. Ann Neurol 64 (1):60-70. doi:10.1002/ana.21425

21. Giordana M.T., Piccinini M., Grifoni S., De Marco G., Vercellino M., Magistrello M., Pellerino A., Buccinna B., Lupino E., Rinaudo M.T. (2010) TDP-43 redistribution is an early event in sporadic amyotrophic lateral sclerosis. Brain pathology (Zurich, Switzerland) 20 (2):351-360. doi:10.1111/j.1750-3639.2009.00284.x

22. Kametani F., Nonaka T., Suzuki T., Arai T., Dohmae N., Akiyama H., Hasegawa M. (2009) Identification of casein kinase-1 phosphorylation sites on TDP-43. Biochem Biophys Res Commun 382 (2):405-409. doi:10.1016/j.bbrc.2009.03.038

23. Salado I.G., Redondo M., Bello M.L., Perez C., Liachko N.F., Kraemer B.C., Miguel L., Lecourtois M., Gil C., Martinez A., Perez D.I. (2014) Protein kinase CK-1 inhibitors as new potential drugs for amyotrophic lateral sclerosis. Journal of medicinal chemistry 57 (6):2755-2772. doi:10.1021/jm500065f

24. Hu J.H., Zhang H., Wagey R., Krieger C., Pelech S.L. (2003) Protein kinase and protein phosphatase expression in amyotrophic lateral sclerosis spinal cord. J Neurochem 85 (2):432-442

25. Hubers A., Ludolph A.C., Rosenbohm A., Pinkhardt E.H., Weishaupt J.H., Dorst J. (2016) [Amyotrophic lateral sclerosis. Multisystem degeneration]. Der Nervenarzt 87 (2):179-188. doi:10.1007/s00115-015-0030-8

26. Silani V., Ludolph A., Fornai F. (2017) The emerging picture of ALS: a multisystem, not only a "motor neuron disease. Archives italiennes de biologie 155 (4):99-109. doi:10.12871/00039829201741 
27. Cova E., Cereda C., Galli A., Curti D., Finotti C., Di Poto C., Corato M., Mazzini G., Ceroni M. (2006) Modified expression of Bcl-2 and SOD1 proteins in lymphocytes from sporadic ALS patients. Neuroscience letters 399 (3):186-190. doi:10.1016/j.neulet.2006.01.057

28. Nardo G., Pozzi S., Mantovani S., Garbelli S., Marinou K., Basso M., Mora G., Bendotti C., Bonetto V. (2009) Nitroproteomics of peripheral blood mononuclear cells from patients and a rat model of ALS. Antioxidants \& redox signaling 11 (7):15591567. doi:10.1089/ars.2009.2548

29. Liu J., Prell T., Stubendorff B., Keiner S., Ringer T., Gunkel A., Tadic V., Goldhammer N., Malci A., Witte O.W., Grosskreutz J. (2016) Down-regulation of purinergic $\mathrm{P} 2 \mathrm{X} 7$ receptor expression and intracellular calcium dysregulation in peripheral blood mononuclear cells of patients with amyotrophic lateral sclerosis. Neuroscience letters 630:77-83. doi:10.1016/j.neulet.2016.07.039

30. Poulopoulou C., Davaki P., Koliaraki V., Kolovou D., Markakis I., Vassilopoulos D. (2005) Reduced expression of metabotropic glutamate receptor 2mRNA in T cells of ALS patients. Ann Neurol 58 (6):946-949. doi:10.1002/ana.20675

31. Allen S.P., Duffy L.M., Shaw P.J., Grierson A.J. (2015) Altered age-related changes in bioenergetic properties and mitochondrial morphology in fibroblasts from sporadic amyotrophic lateral sclerosis patients. Neurobiol Aging 36 (10):2893-2903. doi:10.1016/j.neurobiolaging.2015.07.013

32. Keskin I., Forsgren E., Lange D.J., Weber M., Birve A., Synofzik M., Gilthorpe J.D., Andersen P.M., Marklund S.L. (2016) Effects of Cellular Pathway Disturbances on 
Misfolded Superoxide Dismutase-1 in Fibroblasts Derived from ALS Patients. PLoS One 11 (2):e0150133. doi:10.1371/journal.pone.0150133

33. De Marco G., Lupino E., Calvo A., Moglia C., Buccinna B., Grifoni S., Ramondetti C., Lomartire A., Rinaudo M.T., Piccinini M., Giordana M.T., Chio A. (2011) Cytoplasmic accumulation of TDP-43 in circulating lymphomonocytes of ALS patients with and without TARDBP mutations. Acta neuropathologica 121 (5):611622. doi:10.1007/s00401-010-0786-7

34. Brooks B.R., Miller R.G., Swash M., Munsat T.L. (2000) El Escorial revisited: revised criteria for the diagnosis of amyotrophic lateral sclerosis. Amyotrophic lateral sclerosis and other motor neuron disorders : official publication of the World Federation of Neurology, Research Group on Motor Neuron Diseases 1 (5):293-299

35. Alquezar C., Esteras N., de la Encarnacion A., Alzualde A., Moreno F., Lopez de Munain A., Martin-Requero A. (2014) PGRN haploinsufficiency increased Wnt5a signaling in peripheral cells from frontotemporal lobar degeneration-progranulin $\begin{array}{lllll}\text { mutation } & \text { carriers. } & \text { Neurobiol } & \text { Aging } & 35\end{array}$ (4):886-898. doi:10.1016/j.neurobiolaging.2013.09.021

36. Esteras N., Alquezar C., Bartolome F., de la Encarnacion A., Bermejo-Pareja F., Molina J.A., Martin-Requero A. (2015) G1/S Cell Cycle Checkpoint Dysfunction in Lymphoblasts from Sporadic Parkinson's Disease Patients. Molecular neurobiology 52 (1):386-398. doi:10.1007/s12035-014-8870-y

37. Alquezar C., Salado I.G., de la Encarnacion A., Perez D.I., Moreno F., Gil C., de Munain A.L., Martinez A., Martin-Requero A. (2016) Targeting TDP-43 phosphorylation by Casein Kinase-1delta inhibitors: a novel strategy for the treatment 
of frontotemporal dementia. Molecular neurodegeneration 11 (1):36. doi:10.1186/s13024-016-0102-7

38. Vats A, Gourie-Devi M, Ahuja K, Sharma A, Wajid S, Ganguly NK, Taneja V. (2018) Expression analysis of protein homeostasis pathways in the peripheral blood mononuclear cells of sporadic amyotrophic lateral sclerosis patients. J Neurol Sci. (387):85-91. doi: 10.1016/j.jns.2018.01.035.

39. Nardo G., Pozzi S., Pignataro M., Lauranzano E., Spano G., Garbelli S., Mantovani S., Marinou K., Papetti L., Monteforte M., Torri V., Paris L., Bazzoni G., Lunetta C., Corbo M., Mora G., Bendotti C., Bonetto V. (2011) Amyotrophic lateral sclerosis multiprotein biomarkers in peripheral blood mononuclear cells. PLoS One 6 (10):e25545. doi:10.1371/journal.pone.0025545

40. Alquezar C., Esteras N., Bartolome F., Merino J.J., Alzualde A., Lopez de Munain A., Martin-Requero A. (2012) Alteration in cell cycle-related proteins in lymphoblasts from carriers of the c.709-1G $>$ A PGRN mutation associated with FTLD-TDP

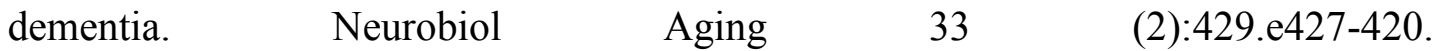
doi:10.1016/j.neurobiolaging.2010.11.020

41. Alquezar C., Esteras N., de la Encarnacion A., Moreno F., Lopez de Munain A., Martin-Requero A. (2015) Increasing progranulin levels and blockade of the ERK1/2 pathway: upstream and downstream strategies for the treatment of progranulin deficient frontotemporal dementia. European neuropsychopharmacology : the journal of the European College of Neuropsychopharmacology 25 (3):386-403. doi:10.1016/j.euroneuro.2014.12.007 
42. Ling S.C., Polymenidou M., Cleveland D.W. (2013) Converging mechanisms in ALS and FTD: disrupted RNA and protein homeostasis. Neuron 79 (3):416-438. doi:10.1016/j.neuron.2013.07.033

43. Burrell J.R., Halliday G.M., Kril J.J., Ittner L.M., Gotz J., Kiernan M.C., Hodges J.R. (2016) The frontotemporal dementia-motor neuron disease continuum. Lancet 388 (10047):919-931. doi:10.1016/s0140-6736(16)00737-6

44. Perez D.I., Gil C., Martinez A. (2011) Protein kinases CK1 and CK2 as new targets for neurodegenerative diseases. Medicinal research reviews 31 (6):924-954. doi:10.1002/med.20207

45. Nonaka T., Suzuki G., Tanaka Y., Kametani F., Hirai S., Okado H., Miyashita T., Saitoe M., Akiyama H., Masai H., Hasegawa M. (2016) Phosphorylation of TAR DNA-binding Protein of $43 \mathrm{kDa}$ (TDP-43) by Truncated Casein Kinase 1delta Triggers Mislocalization and Accumulation of TDP-43. J Biol Chem 291 (11):54735483. doi:10.1074/jbc.M115.695379 
TABLE I

Demographic and clinical characterization of subjects included in this study

\begin{tabular}{|c|c|c|}
\hline & $\begin{array}{l}\text { CONTROL } \\
(n=6)\end{array}$ & $\begin{array}{l}\text { ALS } \\
(n=8)\end{array}$ \\
\hline Gender (M/F) & $(2 / 4)$ & $(5 / 3)$ \\
\hline Family history & No & No \\
\hline \multicolumn{3}{|l|}{ Age $(y \pm S D)$} \\
\hline at sampling & $62 \pm 7$ & $62 \pm 11$ \\
\hline at onset & NA & $60 \pm 12$ \\
\hline \multicolumn{3}{|l|}{ Site of onset (n) } \\
\hline Bulbar & NA & 4 \\
\hline Limb & NA & 3 \\
\hline Respiratory & NA & 1 \\
\hline
\end{tabular}




\section{Legends to the figures}

Figure 1- Cellular content and phosphorylation status of TDP-43 in lymphoblasts from control and ALS patients. A) Immortalized lymphocytes from control and sporadic ALS individuals were seeded at an initial density of $1 \times 10^{6} \mathrm{x} \mathrm{ml}^{-1}$ in RPMI containing $10 \%$ FBS, 24 hours later, cells and were collected and processed to detect phospho- and total-TDP-43 protein levels by Western blotting. Representative immunoblots are shown. Tubulin- $\alpha$ was used as loading control. B) Levels of phosphoTDP-43 (full length and truncated) and total TDP-43. Data represent mean \pm SEM of different experiments carried out with lymphoblastoid cell lines from six control individuals and eight ALS patients. $\left({ }^{*} \mathrm{p}<0.05, * * \mathrm{p}<0.01, * * * \mathrm{p}<0.001\right.$ significantly different from control cells) C) Box plots showing the ratios of phospho-TPP-43/total TDP-43.

Figure 2- Subcellular localization of TDP-43 in control and ALS lymphoblasts. Lymphoblasts from control and ALS patients were seeded and incubated as above. After harvesting, lymphoblasts were lysed to obtain cytosolic and nuclear fragments that were analyzed by Western blotting. Tubulin- $\alpha$ and Lamin B1 antibodies were used as loading and purity control of the cytosolic and nuclear fractions respectively. A representative experiment is shown. Densitometric analyses, shown below, represent the mean $\pm \mathrm{SEM}$ of different observations carried out in four cell lines from each group $\left({ }^{*} p<0.05\right.$, significantly different from control cells. $\uparrow \mathrm{p}<0.05$ significantly different from untreated cells).

Figure 3- Immunofluorescence analysis of the subcellular localization of TDP-43 in control and ALS subjects. Lymphoblasts were seeded at $10^{6}$ cells x ml-1 and incubated for 24 hours. TDP-43 protein localization was assessed by confocal laser scanning 
microscopy. Cells were stained with anti-TDP-43 antibody followed by secondary antibody labeled with Alexa Fluor 488. DAPI was included in the mounting media to stain the nucleus. Merged images show that ALS cells present higher cytosolic localization of TPD-43 protein. Dashed lines marked out the cellular area using visible light. Scale bars $=15 \mu \mathrm{M}$. (B) Quantification of TDP-43 cytosolic localization in lymphoblasts from ALS patients compared to controls. Data are expressed as mean \pm SEM for experiments carried out with four different cell lines for each group $* \mathrm{p}<0.01$ significantly different from control cells.

Figure 4- Effects of the CK-1 $\delta$ inhibitor, IGS 3.27, on TDP-43 phosphorylation. A) The molecular structure and $\%$ of inhibition of $\mathrm{CK}-1 \delta$, and $\mathrm{IC}_{50}$ are shown. B) Immortalized lymphocytes from control and sporadic ALS individuals were seeded at an initial density of $1 \times 10^{6} \mathrm{x} \mathrm{ml}^{-1}$ in absence or presence of IGS3.27 $(5 \mu \mathrm{M}) .24$ hours after drug addition, cells were harvested and processed for Western blotting analysis. The image represents an immunoblot showing the effect of the CK-1 $\delta$ inhibitors decreasing the phosphorylation status of TDP-43 in control and ALS lymphoblasts. C) The plots below represent quantified $43 \mathrm{kDa}$ bands of phosphorylated TDP-43 (left panel) or TDP43 (right panel) normalized by GAPDH. Densitometric analyses represent the mean \pm SEM of different observations carried out in three cell lines from each group $\left({ }^{* *} \mathrm{p}<0.01\right.$ significantly different from control cells. $\dagger p<0.05$ significantly different from untreated cells).

Figure 5- Effects of CK-1 $\delta$ inhibitor, IGS 3.27, on the subcellular localization of TDP-43 in control and ALS lymphoblasts. The experimental conditions are identical to those described in the legend to Fig. 4: $24 \mathrm{~h}$ after treatment with IGS 3.27, lymphoblasts were lysed to obtain both cytosolic and nuclear fragments that were analyzed by Western 
blotting. Tubulin- $\alpha$ and Lamin B1 antibodies were used as loading and purity control of the cytosolic and nuclear fractions respectively. A representative experiment is shown. Densitometric analyses, shown below, represent the mean \pm SEM of different observations carried out in three to five different cell lines from each group $\left({ }^{*} \mathrm{p}<0.05\right.$, significantly different from control cells. $\dagger \mathrm{p}<0.05$ significantly different from untreated cells). 
A
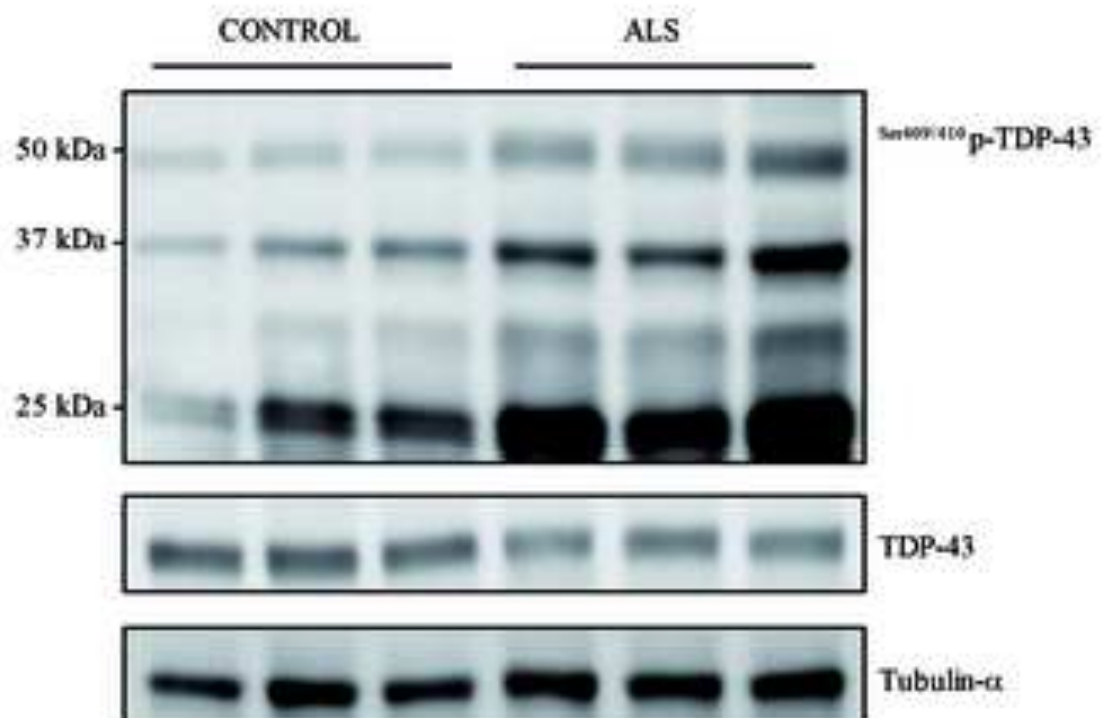

B

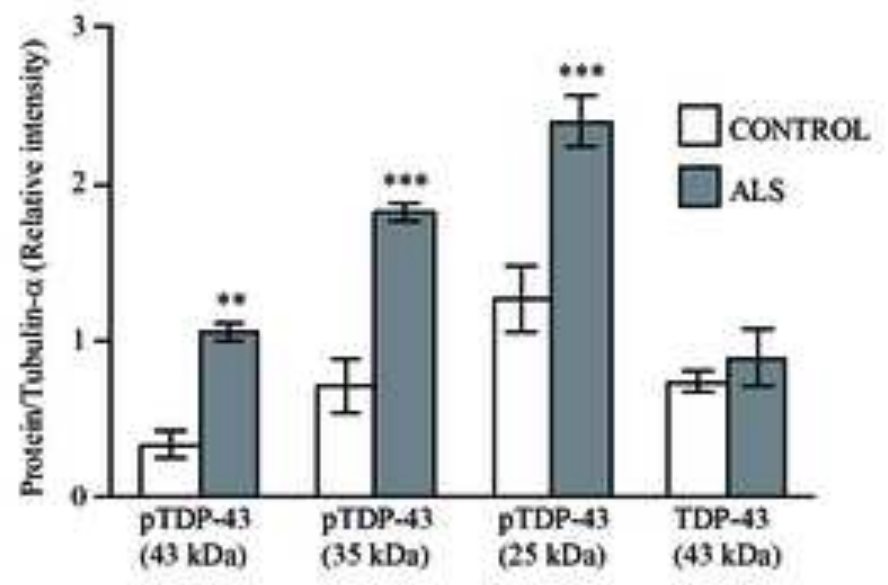

C

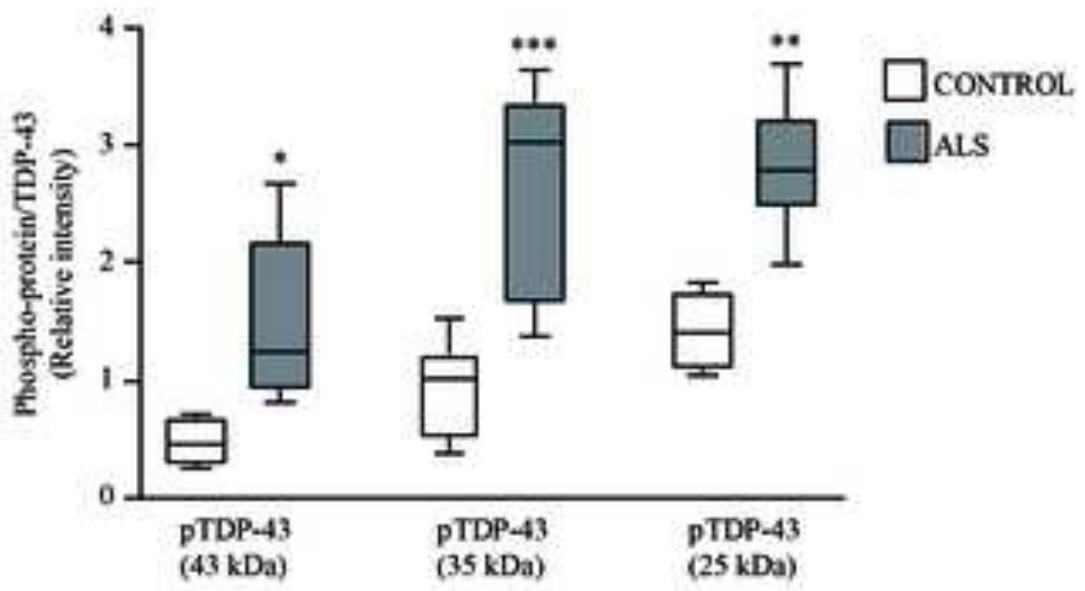

Fig. 1 


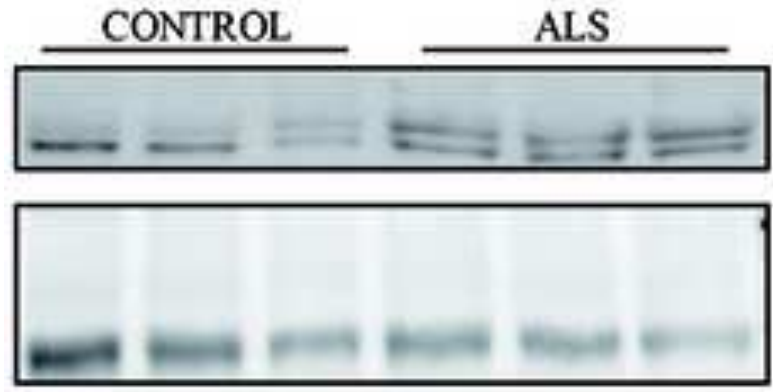

Cytosolic fraction

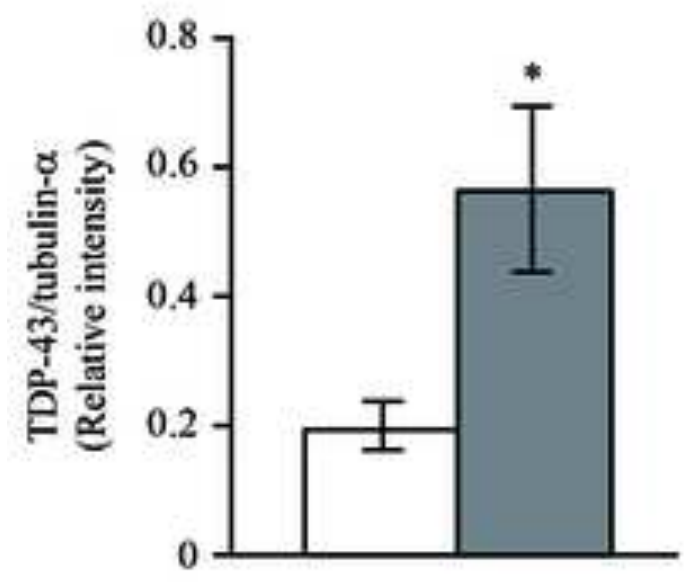

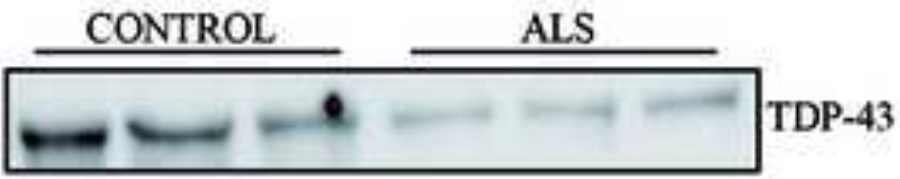

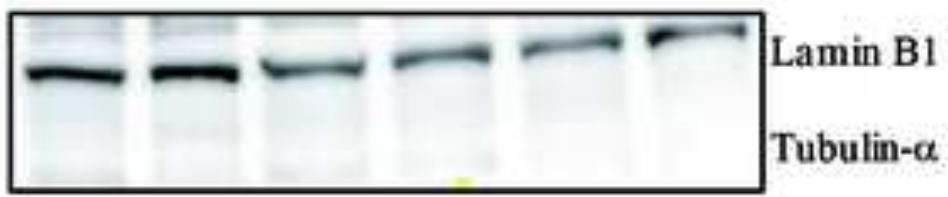

Nuclear fraction

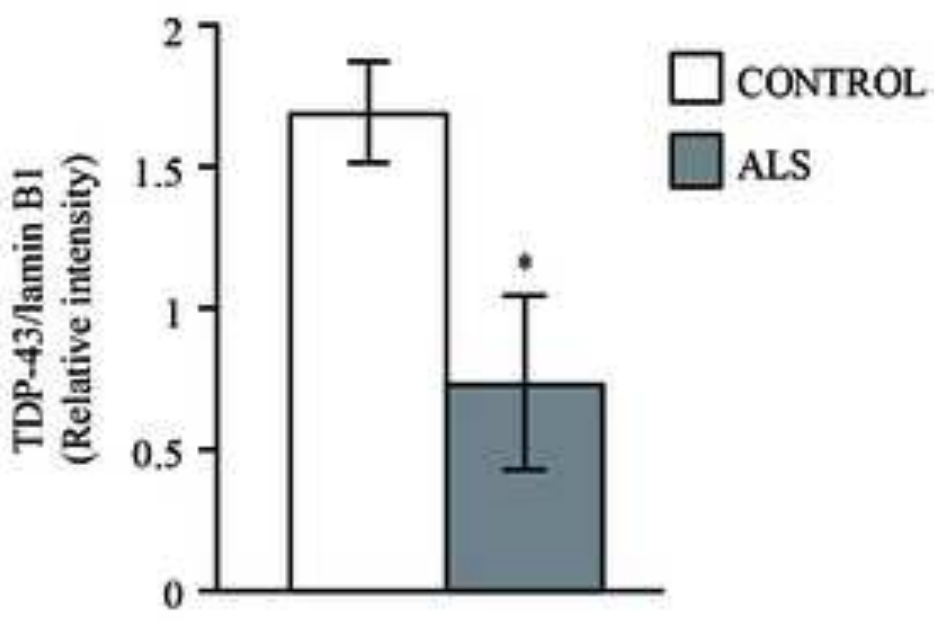

Fig. 2 
A

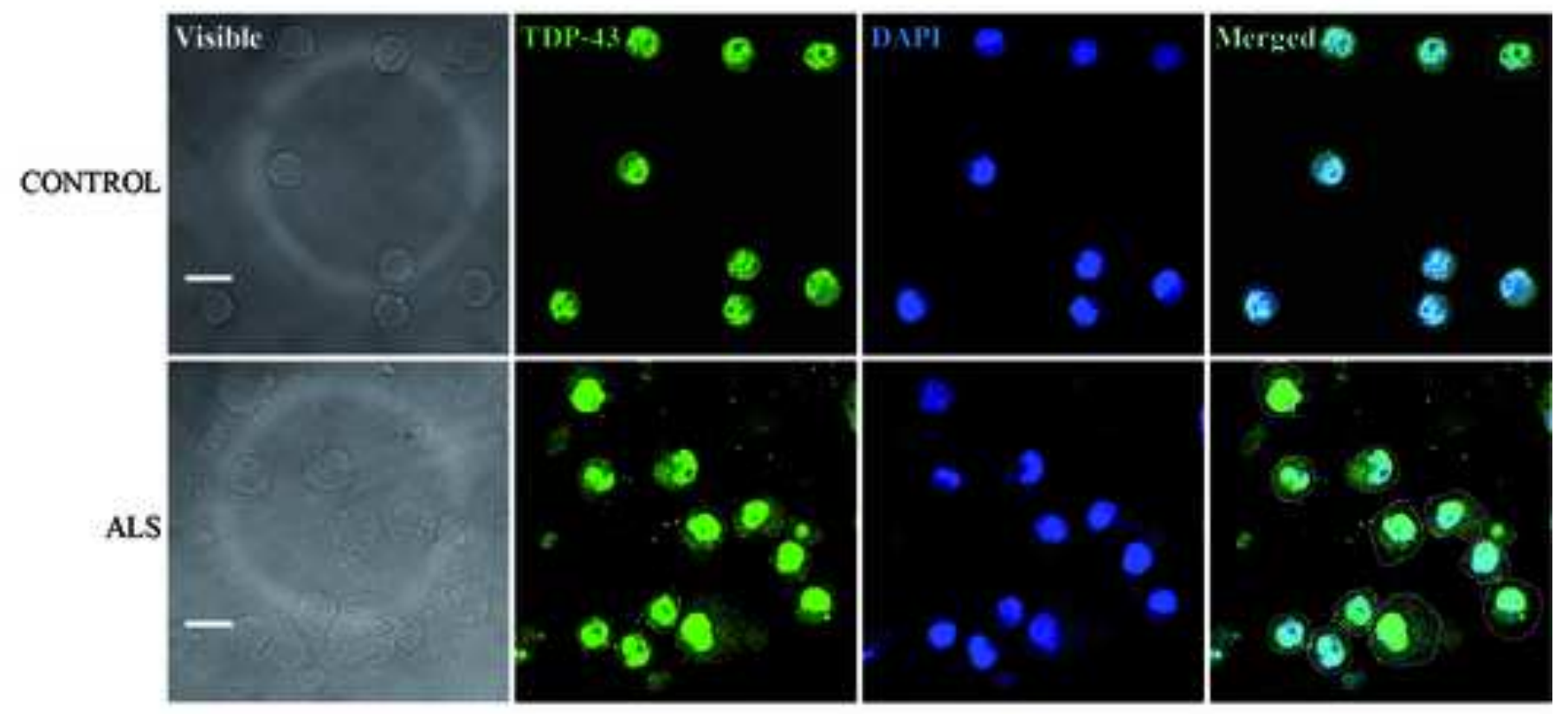

B

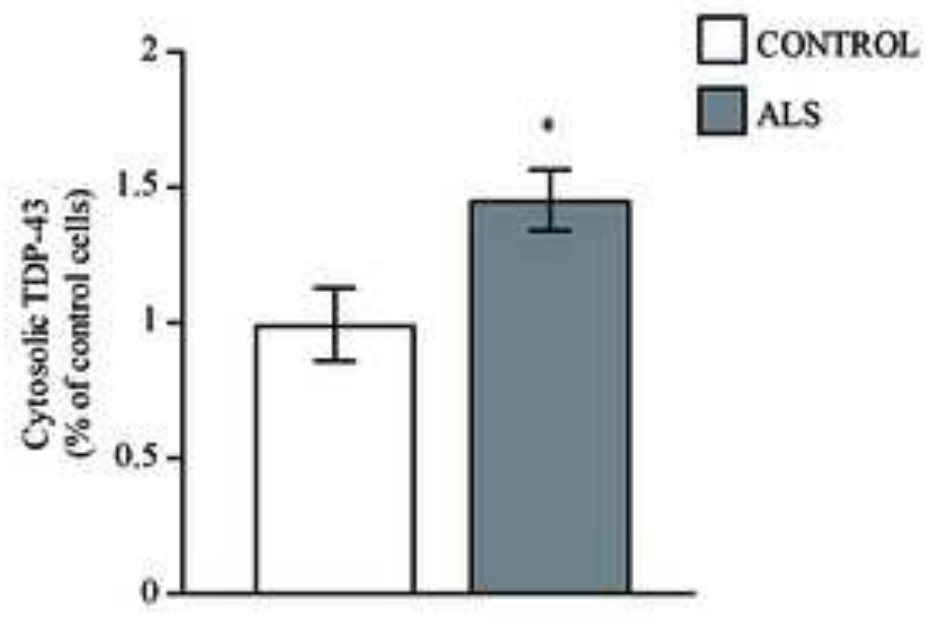

Fig. 3 

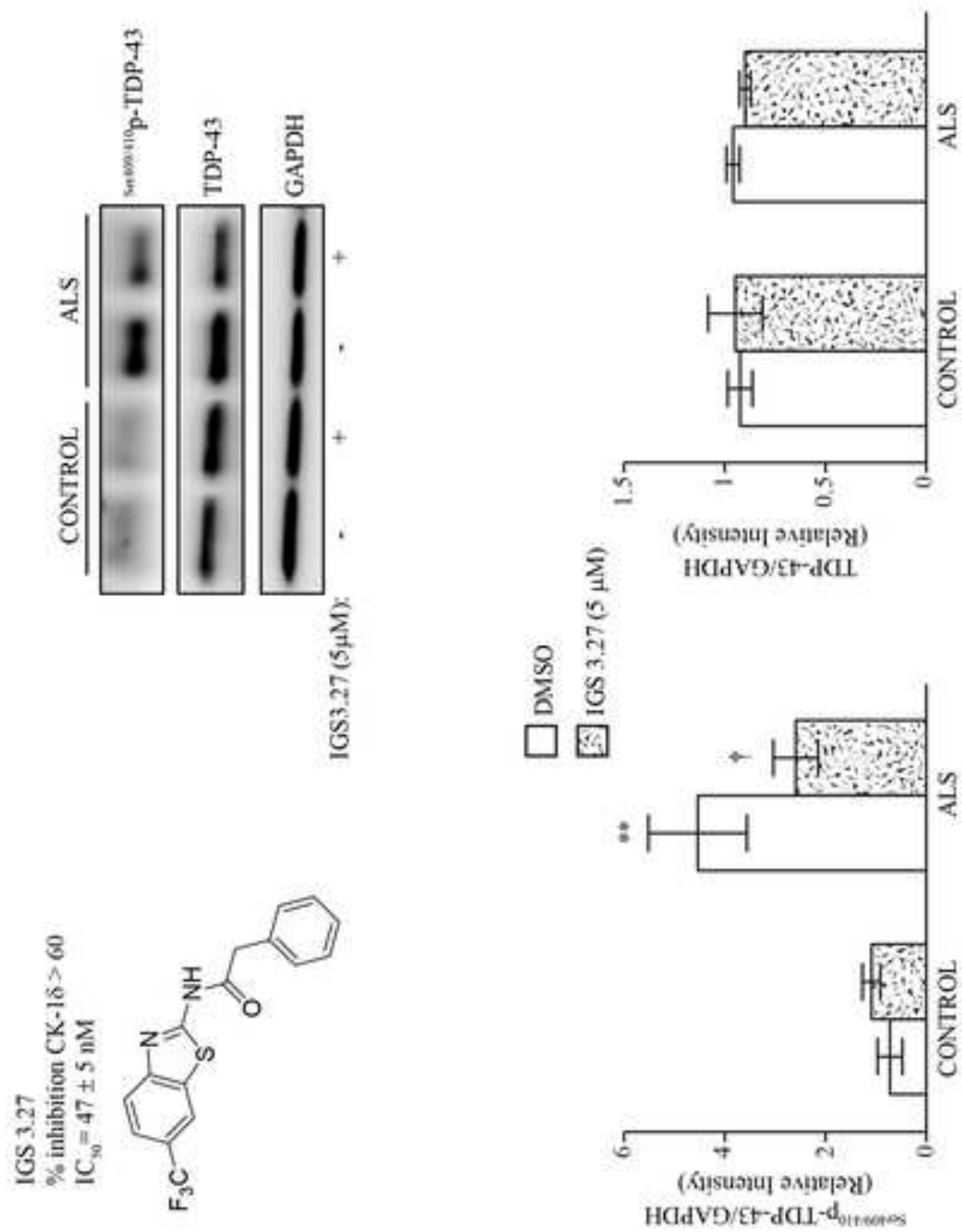

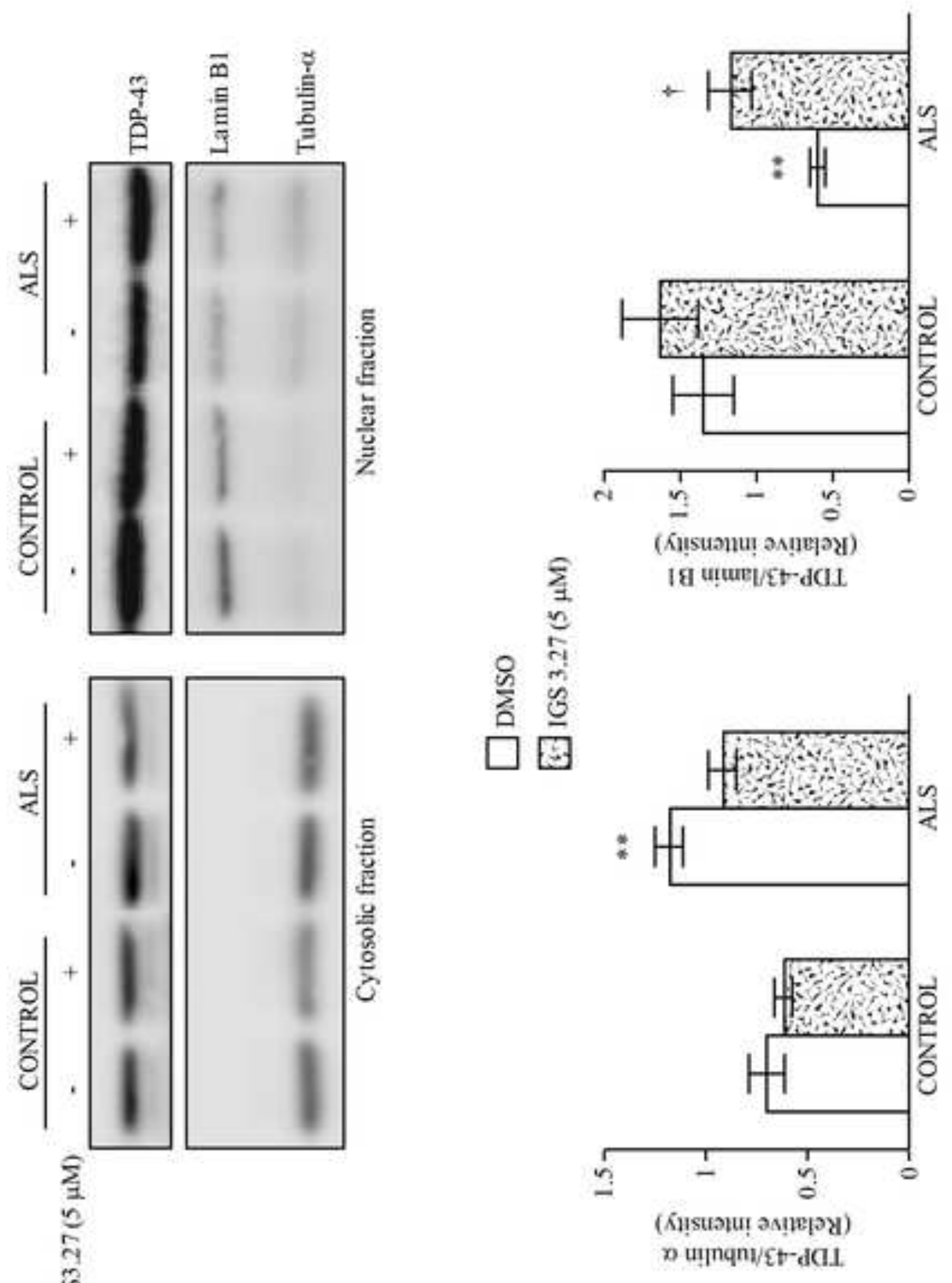

鲁

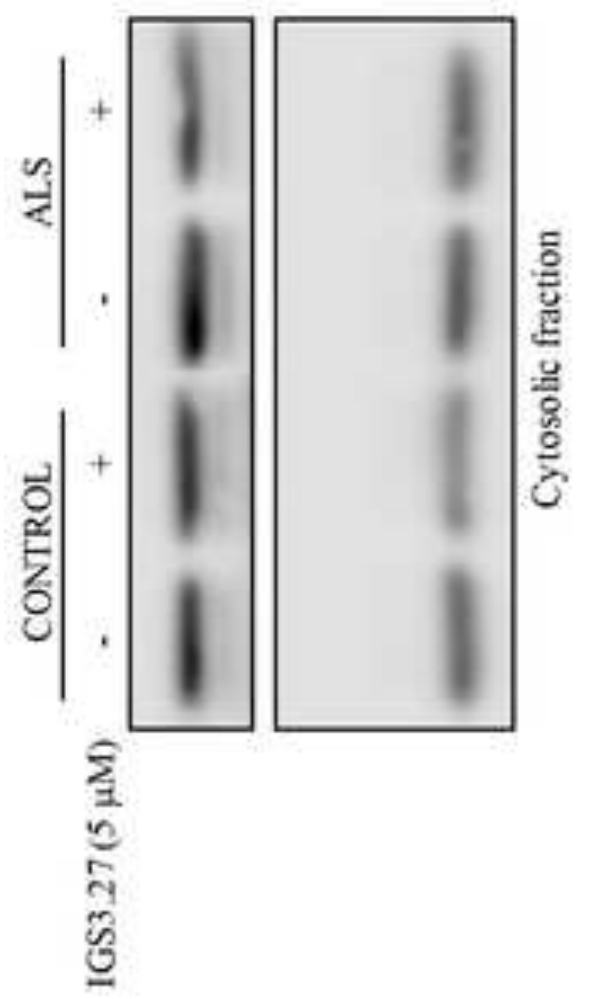

10
0
$\frac{1}{5}$
$i \frac{0}{1}$ 